\title{
BMJ Open Quality Rationalising oxygen usage in a level II special newborn care unit in Madhya Pradesh, India
}

\author{
Jaiprakash Parmar, ${ }^{1}$ Vandana Pawar, ${ }^{1}$ Aarti Warathe, ${ }^{1}$ Manish Singh, ${ }^{2}$ \\ Rajashree Bajaj, ${ }^{2}$ Jogender Kumar, ${ }^{3}$ Anu Thukral, ${ }^{4}$ Deepak Chawla, ${ }^{5}$ \\ Praveen Kumar (D) , ${ }^{3}$ Ashok Deorari (D) ${ }^{4}$
}

To cite: Parmar J, Pawar V, Warathe A, et al. Rationalising oxygen usage in a level II special newborn care unit in Madhya Pradesh, India. BMJ Open Quality 2021;10:e001386. doi:10.1136/ bmjoq-2021-001386

Received 2 February 2021 Accepted 14 April 2021
Check for updates

(C) Author(s) (or their employer(s)) 2021. Re-use permitted under CC BY-NC. No commercial re-use. See rights and permissions. Published by BMJ.

${ }^{1}$ Child Health Division, Special Newborn Care Unit, Sehore, Madhya Pradesh, India ${ }^{2}$ Child Health Division, National Health Mission, Bhopal, India

${ }^{3}$ Department of Pediatrics, Post Graduate Institute of Medical Education and Research (PGIMER), Chandigarh, India ${ }^{4}$ Department of Pediatrics, All India Institute of Medical Sciences (AllMS), New Delhi, India

${ }^{5}$ Department of Pediatrics, Government Medical College and Hospital (GMCH) - 32, Chandigarh, India

Correspondence to Dr Praveen Kumar; drpkumarpgi@gmail.com

\section{ABSTRACT}

Non-judicious oxygen use in preterm infants is associated with increased risk of retinopathy of prematurity, bronchopulmonary dysplasia and longer hospital stay. Despite established guidelines on oxygen therapy, compliance with the best oxygen practices remains suboptimal. Excessive use of oxygen also consumes a large proportion of the annual maintenance budget of special newborn care units (SNCUs) in the districts. In this project, we aimed to reduce the oxygen consumption in the SNCU at Sehore, Madhya Pradesh, India from eight to four cylinders per day, by rationalising the indications, monitoring and method of oxygen delivery. We tested two sets of interventions using the Plan-DoStudy-Act (PDSA) approach. The first intervention was the introduction of a written 'oxygen policy' regarding indications of starting/stopping oxygen and the use of saturation targets. The second was using short binasal infant prongs (at $0.5-1 \mathrm{~L} / \mathrm{min}$ ), instead of oxygen hoods as the primary method of oxygen delivery in spontaneously breathing neonates requiring oxygen. In the first PDSA cycle, we assessed the feasibility of the intervention in a small set $(n=30)$ of neonates and later scaled up to all eligible neonates in the second phase.

We observed a significant reduction in oxygen consumption (from median (IQR) 8 (7-8) to 3 (3-4) cylinders per day) that can lead to a direct saving of 590000 Indian rupees (US\$9000) per year. There was a significant reduction in the number of neonates on oxygen support on a given day. We did not observe any increase in mortality or nasal injury. The change was sustained for the next 8 months.

We conclude that by having a contextual oxygen policy and using nasal prongs instead of oxygen hoods as the preferred delivery method, we can achieve a sustainable reduction in oxygen consumption.

\section{BACKGROUND}

Oxygen is the most used drug in neonatal intensive care units. Though judicious use of oxygen is lifesaving, excessive exposure of preterm neonates to oxygen increases the risk of retinopathy of prematurity (ROP) and bronchopulmonary dysplasia, and prolongs the hospital stay. ${ }^{1}$ Oxygen usage consumes a large proportion of the annual maintenance budget of the special newborn care units (SNCUs) in India. Previous studies have highlighted multiple barriers including limited or no access to pulse oximetry, inadequate staffing, lack of knowledge and training among the healthcare staff in ensuring optimal oxygen therapy in children. ${ }^{23}$ Some of few bottlenecks are system driven and require additional resources, but many of them can be managed using simple interventions. $^{34}$

\section{Problem}

At Sehore SNCU in Madhya Pradesh, India, oxygen consumption was exceedingly high (8-10 jumbo cylinders / day), and a significant portion of the annual maintenance budget was spent on the procurement of oxygen.

\section{Setting}

The government of India has established SNCUs in each district to provide level II care to sick and preterm neonates. The SNCU at Sehore, Madhya Pradesh is a typical 20-bedded, government-funded, level II care unit, staffed by 4 doctors (one paediatrician and three medical officers) and 20 nurses. Sharing of bed by two or more neonates is a common scene. In each shift, a single doctor looks after the neonates as well as emergencies, and attends resuscitation calls. The bedside nurse has a major role and often has to make management decisions, in telephonic consultation with the doctor. The main morbidities among the SNCU admissions are prematurity, low birth weight, respiratory distress, sepsis, birth asphyxia and hyperbilirubinaemia. Nearly 3000 sick neonates are admitted per year, of which $65 \%-70 \%$ receive oxygen. The SNCU has two bubble continuous positive airway pressure (CPAP) machines and used hoods as the primary mode of oxygen delivery. Oxygen is supplied as jumbo cylinders which are connected through a mini-manifold and are refilled as required. The SNCUs follow Facility Based 
Newborn Care (FBNC) guidelines which recommend flow rates of $5-10 \mathrm{~L} / \mathrm{min}$ while using an oxygen hood. ${ }^{5}$

\section{Rationale}

Oxygen hood is a high-flow device $(4-6 \mathrm{~L} / \mathrm{min})$ and leads to a lot of wastage, whereas nasal prongs are low-flow devices requiring a flow rate of $0.5-1 \mathrm{~L} / \mathrm{min}$ in neonates. We can save 5000-7000 L of oxygen per neonate per day, by switching from hood to nasal prongs. The WHO strongly recommends use of nasal prongs for neonates. ${ }^{6}$ If we follow the best practices of oxygen therapy, a significant reduction in consumption can be achieved.

\section{Specific aim}

We aimed to reduce the oxygen consumption in Sehore SNCU from eight cylinders per day to four cylinders per day (50\% reduction) within 8 weeks using a quality improvement (QI) approach.

\section{METHODS}

Design

We executed the following steps: (1) formation of a QI team comprising SNCU in-charge paediatrician, one medical officer and two nurses; (2) collection of baseline data comprising daily admissions, number of infants receiving respiratory support (oxygen hood and CPAP) on a given day, duration of oxygen therapy, number of oxygen cylinders consumed per day and mortality for 3 weeks (1-21 December 2017); (3) identification of possible reasons for increased oxygen consumption using fishbone analysis (figure 1); (4) group discussion to elicit change ideas; and (5) testing change ideas using a series of Plan-Do-Study-Act (PDSA) cycles.

\section{Measurements and analysis}

Our primary outcome measure was the number of oxygen cylinders consumed per day. As a balancing measure, we tracked the number of admissions, the number of neonates receiving oxygen, CPAP and mortality. The SNCU online database was used to extract some of these parameters including the duration of hospital stay and duration of oxygen use for more than 24 hours. There were concerns from the staff that the cost of nasal prongs will add to the budget, therefore, we also did a crude cost analysis. We used descriptive statistics for the baseline variables and $\mathrm{X}^{2}$ test or one-way analysis of variance or Kruskal-Wallis test as applicable for comparison of the parameters across the epochs. We used run charts to display the serial measurements. SPSS V.21 was used for statistical analysis and a p value of less than 0.05 was taken as significant. We used Standards for Quality Improvement Reporting Excellence V.2.0 guidelines for reporting. ${ }^{7}$

\section{Patient involvement}

Patients were not directly involved in the implementation.

\section{Strategy}

We used the PDSA cycle approach for quality improvement. Feasibility was tested in PDSA cycle 1 . Various interventions were tested in three subphases during PDSA cycle 2 . These were followed by the sustenance phase. The details of various PDSA cycles are described in table 1.

\section{PDSA cycle \#1}

In the first PDSA cycle (22 December 2017-5 January 2018), we drafted an 'oxygen policy' after having group discussions involving SNCU in-charge paediatrician, medical officers and the staff nurses. The policy was approved by the chief medical officer of the hospital.

\section{Fishbone Diagram}

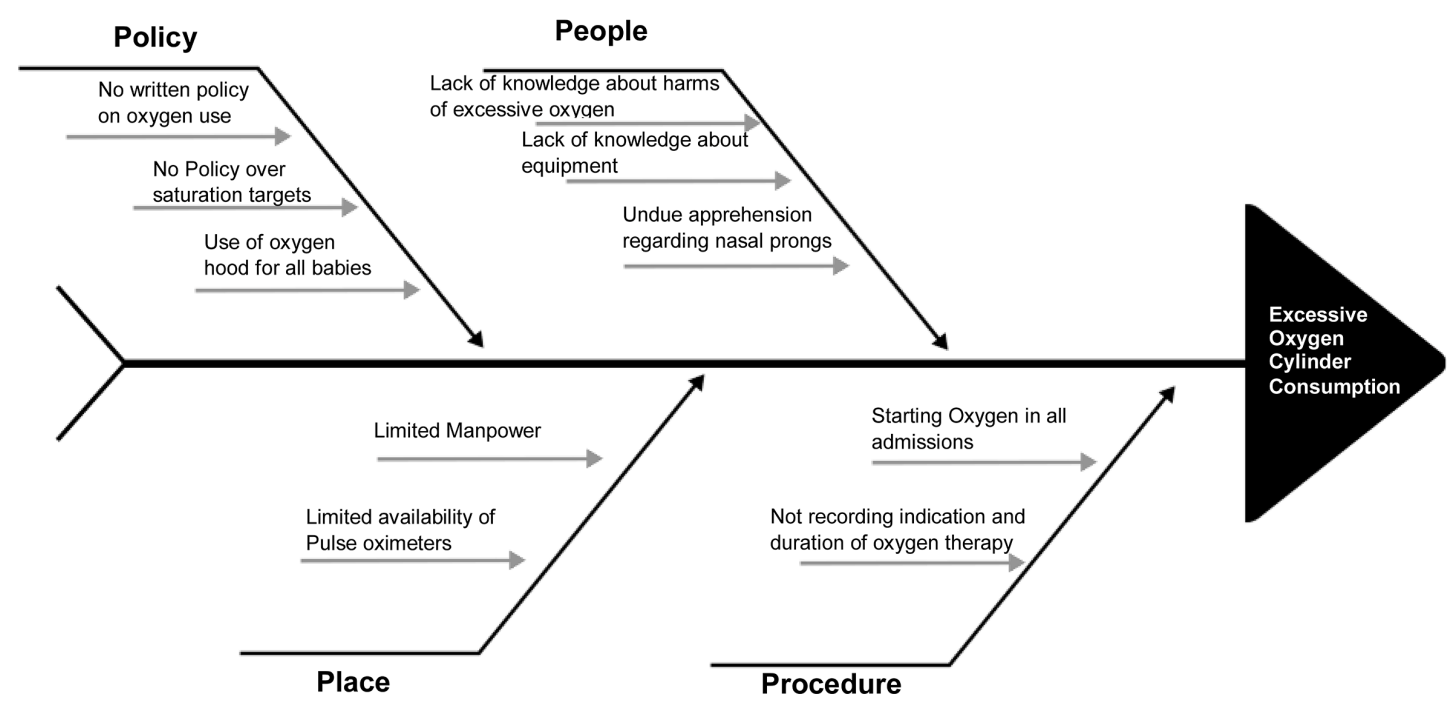

Figure 1 Fishbone diagram for root cause analysis. 


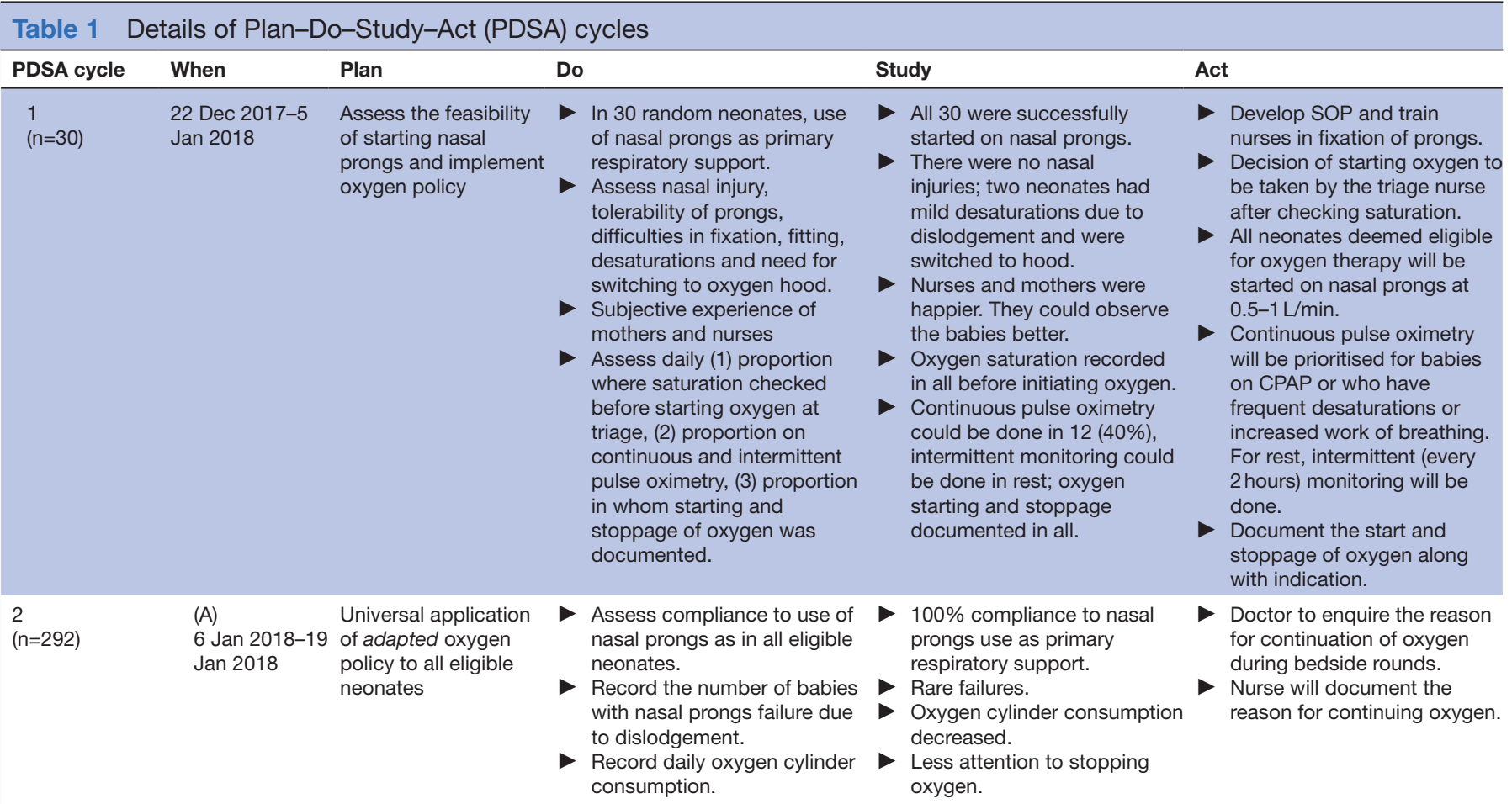

(B)

20 Jan 2018-2

Feb 2018

(C)

3 Feb 201816 Feb 2018
All above+

- Ongoing education and sensitisation of staff, weekly meetings and appreciating weekly champions.

All above+

Training of nurses in assessing severity of respiratory distress to identify babies needing CPAP and empowering them to initiate CPAP.
- In 2 neonates with moderate respiratory distress, hiking of respiratory support from nasal prongs to CPAP was delayed.

- Daily number of babies on oxygen decreased, however number of admissions remained the same

- Number of neonates receiving CPAP increased.

- No change in nasal injury and mortality rates

\begin{tabular}{|c|c|c|c|c|c|}
\hline $\begin{array}{l}\text { Sustenance } \\
\text { phase } \\
(n=1005)\end{array}$ & $\begin{array}{l}21 \text { Feb 2018-30 } \\
\text { Sep } 2018\end{array}$ & $\begin{array}{l}\text { Dissemination and } \\
\text { regular audit plan }\end{array}$ & & $\begin{array}{l}\text { Disseminate the final policy } \\
\text { and SOP. } \\
\text { Record cylinder } \\
\text { consumption. } \\
\text { Monthly meeting, audit, } \\
\text { refresher training and } \\
\text { feedback. }\end{array}$ & $\begin{array}{l}\text { Monthly audits } \\
\text { Compliance with oxygen } \\
\text { policy } \\
\text { Number of admissions, } \\
\text { number of babies receiving } \\
\text { oxygen, number of oxygen } \\
\text { cylinders used. } \\
\text { Mortality. }\end{array}$ \\
\hline
\end{tabular}

CPAP, continuous positive airway pressure; SOP, standard operating procedure.

The key highlights of the policy were (1) at admission triage, the staff nurse will first check oxygen saturation and assess for respiratory distress, and the decision for starting oxygen will be based on these two parameters. The previous practice was to first start oxygen by the hood in all babies reporting to the triage and then do the assessments. (2) All those who meet the criteria for oxygen supplementation shall be started on nasal prongs oxygen at $0.5-1 \mathrm{~L} / \mathrm{min}$. The contraindications of using nasal prongs will be the presence of congenital airway anomaly, pre-existing nasal trauma or poor respiratory efforts. (3) Whenever possible, continuous pulse oximetry will be used and oxygen flow in the nasal prongs titrated based on saturation targets. If number of pulse oximeters is not sufficient, intermittent readings will be taken every
2 hours. (4) The starting and stoppage of oxygen therapy will be documented along with the indications.

The staff were in agreement on all aspects of the policy, except the universal use of nasal prongs. They were apprehensive as they had not used them earlier. Therefore, our first PDSA cycle aimed at assessing the feasibility and safety of using nasal prongs. We randomly enrolled 30 neonates (two neonates per day) needing oxygen as per policy and applied nasal prongs in them. To assess the safety and feasibility of using nasal prongs, we recorded details of nasal trauma, tolerability of prongs, any difficulty in using prongs, whether the prongs fit well or not, and desaturations if any. In the case of desaturations, the nurses first ensured that the prongs were within the nostrils and properly fixed, and then hiked the flow rate 
to $1 \mathrm{~L} / \mathrm{min}$. If the desaturations persisted, they switched to oxygen hood or CPAP depending on the severity of respiratory distress. In this PDSA involving 30 neonates, we observed desaturations in two neonates. Both neonates were on continuous pulse oximetry monitoring and the desaturations were mild. During these episodes, the nasal prongs were found dislodged from the nostrils due to improper fixation. Following this, a standard operating procedure was created for the fixation of nasal prongs, and all nurses were trained until they became confident. To assess compliance to the new oxygen policy, we recorded the following parameters on daily basis: (1) proportion of neonates reporting to triage, in whom the staff nurse first checked oxygen saturation before starting oxygen, (2) proportion of neonates on oxygen in whom continuous and intermittent pulse oximetry were used, (3) proportion of neonates on oxygen, in whom starting, and stoppage of oxygen was documented.

During this PDSA, the team confirmed that we do not have enough pulse oximeters for continuous monitoring of all neonates on oxygen. However, intermittent monitoring was feasible in all neonates on supplemental oxygen. Therefore, we decided to prioritise the continuous saturation monitoring for neonates who were on CPAP support or who were having frequent desaturations or increased work of breathing. For stable neonates on supplemental oxygen, we planned to use continuous pulse oximetry only if a pulse oximeter was spare, else to use 2-hourly intermittent monitoring.

\section{PDSA cycle \#2}

We conducted the second PDSA from 6 January to 16 February 2018, over 6 weeks targeting all admitted neonates requiring oxygen therapy. This PDSA cycle had three subphases A, B and C (table 1). We continued the ongoing training comprising education about the revised oxygen policy, saturation targets, importance of pulse oximetry and early identification of nasal trauma. To keep the enthusiasm, we held weekly meetings to discuss the progress and introduced the practice of recognising the nurse champion of the week who showed the best compliance to the oxygen policy in the past week. After 2 weeks, we noticed that the nurses were confident in deciding when to start oxygen therapy, but less attention was being given to stopping oxygen. Therefore, we introduced a new change that in each shift, the doctor will enquire the reason for continuing oxygen therapy in the bedside rounds and the nurse will document the reason in the notes. During this period, the team identified two neonates with moderate respiratory distress, in whom the hiking of respiratory support from nasal prongs to CPAP was delayed. The reason was inability of the physician to visit and examine the infants to take a decision, due to preoccupation in the delivery room. Discussions revealed that this was not an uncommon scenario. In the weekly team meeting, it was decided to train the nurses for better identification of moderate to severe respiratory distress and empower them to initiate CPAP. With the help of videos and demonstrations, they were trained to categorise the severity of respiratory distress and identify those needing CPAP. They were authorised to initiate CPAP with information to the on-call duty doctor. As the nurses were confident in using nasal prongs, in this phase, we limited data recording to the number of babies admitted, number requiring oxygen, number of oxygen cylinders consumed, nasal injury and mortality.

\section{Sustenance phase}

Following the two PDSA cycles, the use of nasal prongs became a routine practice instead of oxygen hood, and the staff were happy about it. The initially drafted oxygen policy was modified and finalised to accommodate the learning and changes made during its testing. During this phase (21 February 2018-30 September 2018), we continued with monthly audits of compliance to components of oxygen policy, number of admissions, number of babies receiving oxygen, oxygen cylinder consumption and mortality.

\section{RESULTS}

In the baseline period, a total of 133 neonates were admitted, of whom 107 (80.4\%) received oxygen. Among them, $68(64 \%)$ received oxygen for more than 24 hours. All were given oxygen through hood and on average, eight jumbo oxygen cylinders were consumed per day.

In the first PDSA (feasibility phase), in 2 of the 30 neonates, there were recurrent but mild desaturations due to improper fixation, and both neonates were switched to headbox. In the remaining 28 of 30 neonates, we did not face any difficulty in using nasal prongs and they tolerated it very well. None of the neonates had nasal trauma. In all 30 neonates, nurses first checked oxygen saturation at triage before deciding to start oxygen. Continuous pulse oximetry was used in 12 (40\%) neonates only, however, we were able to record and document intermittent oxygen saturation at 2-hourly intervals, in all eligible neonates. The nurses documented the time and reason for starting and stopping oxygen therapy in all 30 neonates.

During the second PDSA cycle (intervention phase), a total of 296 neonates were admitted, of whom 230 (77.8\%) received oxygen therapy at admission. As compared with baseline, there were no differences in the demographic parameters or proportion of neonates requiring oxygen at admission (table 2). We observed a significant reduction in the consumption of oxygen cylinders from median (IQR) 8 (7-8) per day to 3 (3-5) per day (figure 2 ). Moreover, this change was sustained over the next 8 monthsmedian (IQR) 3 (3-4) (figure 3).

With the introduction of 'oxygen policy' and changes made in it during the second PDSA cycle, we were able to discontinue oxygen within 24 hours of admission in a significantly higher proportion of neonates who were started on oxygen at admission, as compared with the baseline situation $(64.7 \%$ vs $36.4 \%, \mathrm{p}<0.001)$ (table 2). This led to a $45 \%$ reduction in the number of neonates 
Table 2 Comparison of parameters between three epochs

\begin{tabular}{|c|c|c|c|c|}
\hline Parameter & $\begin{array}{l}\text { Baseline } \\
\text { ( } 3 \text { weeks) }\end{array}$ & $\begin{array}{l}\text { Feasibility phase } \\
\text { (15 days) }\end{array}$ & $\begin{array}{l}\text { Intervention } \\
\text { phase } \\
\text { (6 weeks) }\end{array}$ & P value* \\
\hline No of neonates admitted & 133 & 101 & 296 & \\
\hline $\begin{array}{l}\text { Gestational age (weeks) } \\
\text { Mean (SD) }\end{array}$ & $36.4(1.9)$ & $35.9(2.2)$ & $36.3(1.9)$ & 0.1 \\
\hline $\begin{array}{l}\text { Birth weight (grams) } \\
\text { Mean (SD) }\end{array}$ & $2443(576)$ & $2376(614)$ & $2375(588)$ & 0.6 \\
\hline $\begin{array}{l}\text { Age at admission } \\
\text { Median (1st-3rd quartile) }\end{array}$ & $0(0-4)$ & $0(0-2)$ & $0(0-3)$ & 0.5 \\
\hline Male & $82(61.7)$ & $73(72.3)$ & $176(59.5)$ & 0.07 \\
\hline $\begin{array}{l}\text { Hospital stay (days) } \\
\text { Median (1st-3rd quartile) }\end{array}$ & $2(1-4)$ & $2(1-3)$ & $2(1-3)$ & 0.009 \\
\hline Oxygen cylinder consumption median (IQR) & $8(7-8)$ & $8(7-8)$ & $3(3-5)$ & \\
\hline Nasal injury & 0 & 0 & 0 & - \\
\hline Died at hospital & $12(9.0)$ & $8(7.9)$ & $17(5.7)$ & 0.4 \\
\hline
\end{tabular}

Values are presented as $n(\%)$ unless specified.

${ }^{*} \mathrm{X}^{2}$ test/one-way ANOVA/Kruskal-Wallis test as applicable.

†Denominator is number of neonates requiring oxygen.

ANOVA, analysis of variance.

on oxygen on a given day from a median of 11 per day to 6 per day (figure 4A).

As balancing measures, we also tracked the mortality and the number of neonates requiring higher respiratory support (CPAP). There was no significant difference in mortality in the baseline, feasibility phase and intervention phases. However, we observed a significant increase in the daily number of neonates on CPAP support (figure 4B). It most likely reflects the effect of education and empowerment of nurses in identification of moderate to severe respiratory distress and timely hiking of respiratory support. In the pre-intervention

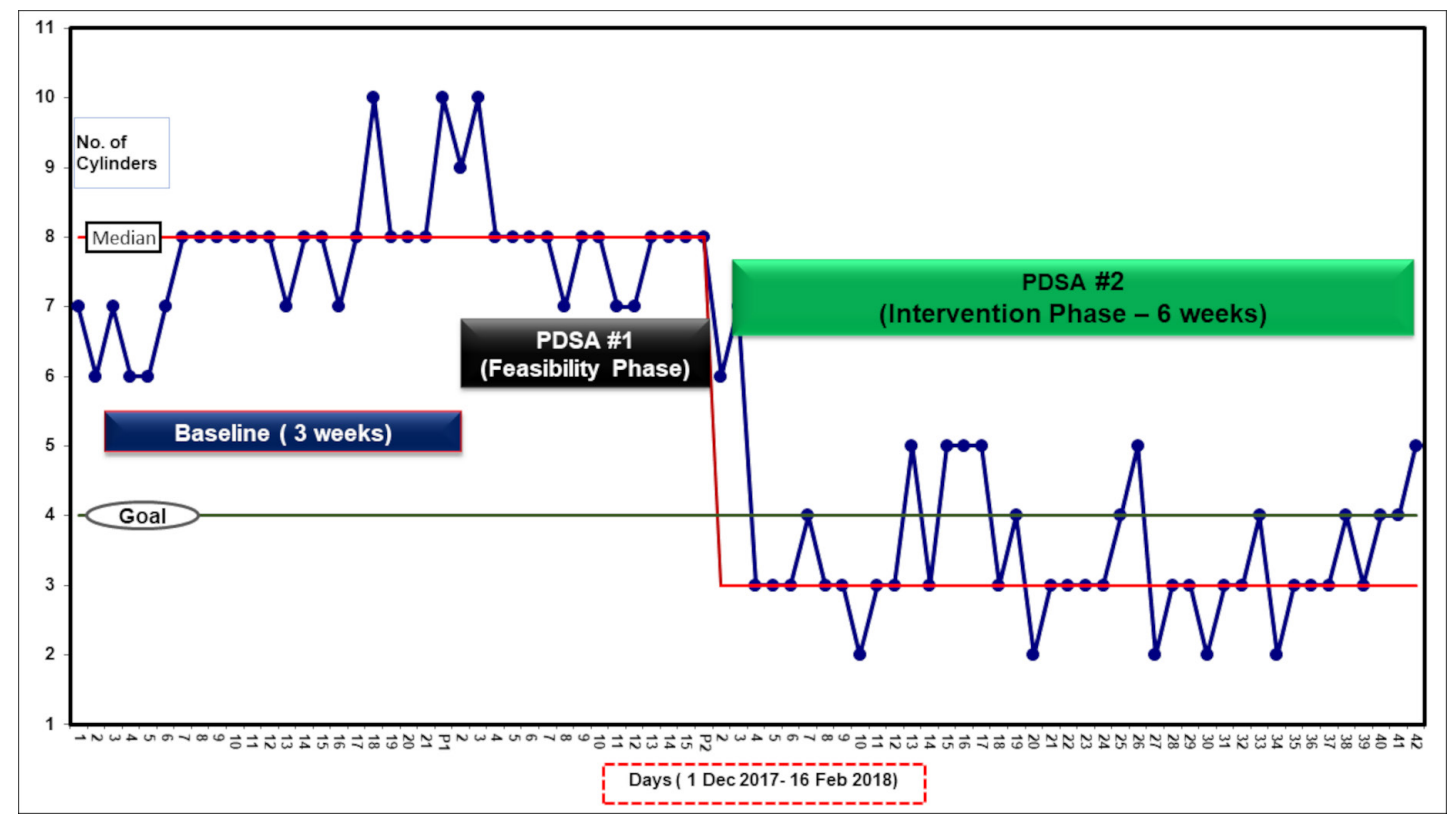

Figure 2 Run chart showing the number of oxygen cylinders consumed per day during the baseline, feasibility and intervention phase. PDSA, Plan-Do-Study-Act. 


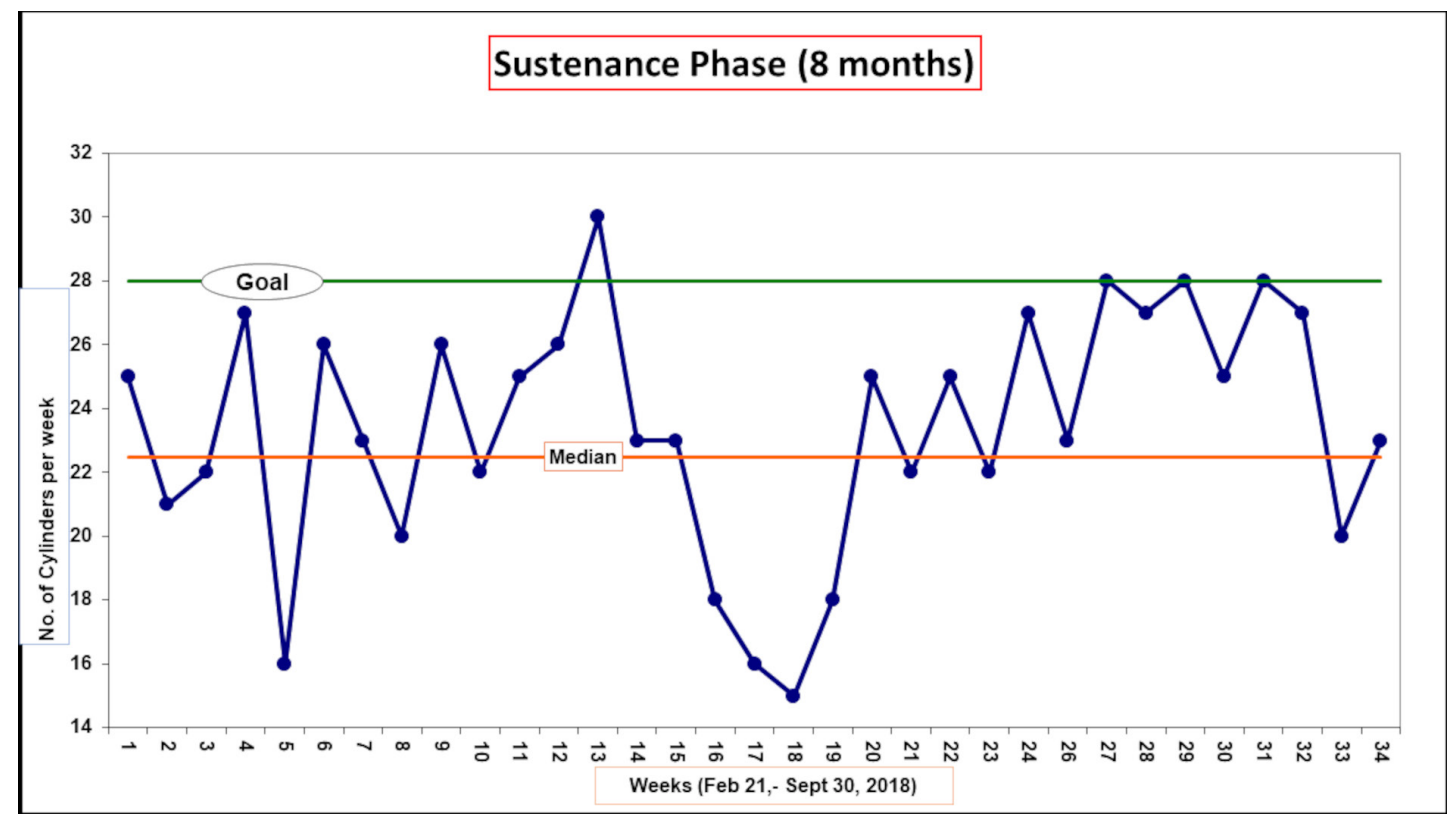

Figure 3 Run chart showing the number of oxygen cylinders consumed per week during sustenance phase.

period, if a neonate had worsening respiratory distress, the bedside nurse used to increase the oxygen flow rate and waits for the doctor to examine the baby and take a decision. As there is a single doctor in a shift attending to SNCU babies, outpatient department as well as delivery room, and doing administrative work, this often led to delay. Therefore, the nurses were trained in timely identification of moderate to severe respiratory distress and empowered to initiate CPAP. They were also retrained in setting up of CPAP machine and titrating the positive end expiratory pressure and fractional inspired oxygen as per need. We also observed a significant reduction in the daily census in the intervention phase (figure $4 \mathrm{C}$ ) as well as the overall duration of hospital stay for each neonate (table 2). As there was no reduction in weekly admissions (rather there was an $11 \%$ increase), this change is likely a result of early weaning from oxygen therapy combined with another QI initiative of early initiation and rapid advancement of feeds.

\section{Qualitative feedback}

We received positive feedback from the nurses and mothers. Nurses felt that it was easy to apply and maintain nasal prongs. Also, it was much easier to observe the babies and administer gavage feeds to neonates on nasal prongs. Mothers were also happy that they can even

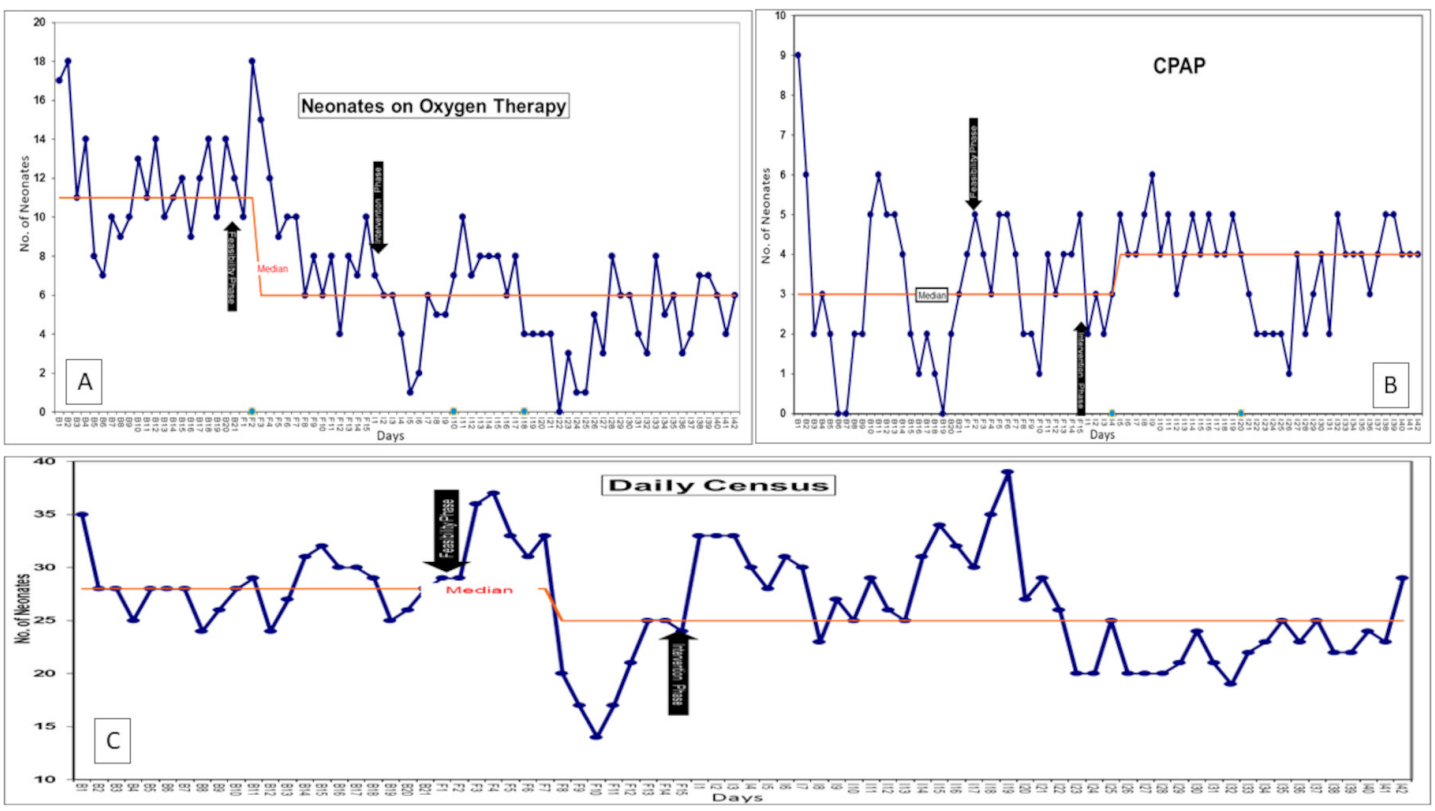

Figure 4 Run charts showing (A) number of neonates on oxygen, (B) CPAP and (C) total census, on a given day. CPAP, continuous positive airway pressure. 
breast feed their babies while they are on nasal prongs, which was not feasible previously on oxygen hoods.

\section{Cost analysis}

There was apprehension that the use of disposable nasal prong for each neonate requiring oxygen will incur additional costs and may further adversely affect the budget. Therefore, we did a crude cost analysis taking existing rates and conversion units of March 2018 into account. In March 2018, the cost of refilling a jumbo oxygen cylinder was 360 Indian rupees (approximately US\$5.5), and that of nasal prong was 15 Indian rupees (approximately US\$0.2). During the baseline period of 3 weeks, we spent approximately 57000 Indian rupees (79\% of maintenance budget of this period) on refilling of oxygen cylinders. During the intervention (6 weeks) and sustenance (32 weeks) phases, the total expenditure for refilling and nasal prongs was 63210 Indian rupees (42\% of budget) and 288000 Indian rupees (38\% of maintenance budget), respectively. As compared with the baseline, we saved 260 Indian rupees (US\$4) per neonate requiring oxygen, during the intervention phase and 295 Indian rupees (US\$4.5) during the sustenance phase. This does not include the savings on the cost of oxygen hoods. Annually about 2000 neonates receive oxygen in the SNCU and this can translate to a saving of US\$9000 ( $48 \%$ of annual maintenance budget).

\section{DISCUSSION}

We showed a significant and sustained decline in the consumption of oxygen cylinders using the principles of QI, within existing resources and manpower. We could achieve a $63 \%$ reduction in the consumption of oxygen cylinders and more than $40 \%$ of the annual maintenance budget. The interventions were simple and can be replicated in any resource-limited settings. The savings from the budget can be used for other essential requirements like meeting the shortage of pulse oximeters.

In the first cycle of PDSA, everyone agreed that there is a need for an 'oxygen policy' and we should actively look for opportunities to stop oxygen early. In India, FBNC guidelines of 2011 are followed in all SNCUs. FBNC guidelines endorse all the components of oxygen policy formulated by us except the use of nasal prongs. The FBNC guidelines give option of using nasal prongs or oxygen hood or nasal catheter. ${ }^{5}$ The updated WHO guidelines recommend the use of nasal prongs and were shared and discussed with the team members. ${ }^{6}$ However, as with any change in practice, initially there were apprehensions for using nasal prongs. We valued the team's apprehensions and concerns and tested the change at a small scale. The problems faced in the small test were addressed and the confidence of the staff increased. The acceptance by the nursing staff and their active participation is reflected in the sustenance of the change after 8 months. The nursing staff felt that they had become more confident in managing neonates on oxygen and taking decisions of increasing or downgrading the respiratory support. The cost analysis helped in convincing the state policymakers and administrators. They were happy to ensure a regular supply of nasal prongs and extend the practice to other SNCUs of the state.

Oxygen is the most commonly misused drug in the neonatal period. ${ }^{8}$ Studies have shown that irrespective of the diagnosis, more than $90 \%$ of the spontaneously breathing infants receiving oxygen by headbox are hyperoxemic. ${ }^{9}$ Most of the level II SNCUs in India face overcrowding and lack sufficient pulse oximeters for continuous oxygen saturation monitoring, therefore further increases the risk of adverse effects (like ROP) secondary to hyperoxemia. The WHO updated its oxygen policy in 2016 and recommended using nasal prongs while discouraging the used of oxygen hood. The forthcoming revision of national FBNC guidelines will be modifying the recommendations in favour of using nasal prongs. Active efforts are required to reduce the gaps between evidence and policy in a timely manner. This can be achieved by formulation of scientific expert groups in collaboration with professional associations, tasked with providing real-time updates in policies. The utilisation of oxygen in the SNCUs should be evaluated regularly and correlated with ROP rates and all-cause mortality.

There is inadequate knowledge and lack of adherence to saturation targets. ${ }^{10}$ Nurses can play a pivotal role in ensuring optimal oxygen therapy and therefore reducing its undesirable consequences like ROP. ${ }^{11}$ Similar context adapted changes in the oxygen delivery practices have helped in achieving better compliance to the best oxygen therapy practices in other settings. ${ }^{341213}$ With improving survival of premature neonates in level II SNCUs, the ROP burden is also increasing, and by using packages of simple QI measures, we can contribute to controlling the third epidemic of ROP in developing countries. ${ }^{14}$ We could not assess the impact on ROP during the study period because of transfer-out of the district ophthalmologist.

\section{CONCLUSION}

We were able to rationalise and reduce the use of oxygen in the SNCU by introducing a context-specific oxygen policy and adapting it as per recommended best practices. We were able to reduce the amount of oxygen consumed and save a significant amount of annual maintenance budget. Twitter Anu Thukral @dranu2014 and Praveen Kumar @praveenpginicu

Acknowledgements We would like to extend our sincere thanks to the whole team of SNCU Sehore and numerous officials of National Health Mission, Madhya Pradesh. This opportunity and initiative would not have been possible without the funding grant by Queen Elizabeth Diamond Jubilee Trust, UK for the primary project of 'Reducing blindness due to retinopathy of prematurity by improving quality of care in special care newborn units'. Our heartfelt gratitude for the same is due to Professor Claire Gilbert of London School of Tropical Medicine, Professor GVS Murthy and Dr Rajan Shukla of Indian Institute of Public Health, Hyderabad, India.

Contributors DC, PK and AD conceptualised and supervised the study, helped in data analysis and critically reviewed the manuscript. JP, VP and AW collected and analysed the data. JP and JK analysed and interpreted the data and drafted the manuscript. MS and RB provided intellectual inputs in the design of the study, 
data analysis, and drafting and critically reviewing the manuscript. All the authors approved the final version to be published and agreed to be accountable for all aspects of the work.

Funding This quality improvement work was part of a project on 'Reducing blindness due to retinopathy of prematurity by improving quality of care in special care newborn units' funded by Queen Elizabeth Diamond Jubilee Trust, UK. Publication of this article is made open access with funding from the Nationwide Quality of Care Network.

Competing interests None declared.

Patient and public involvement Patients and/or the public were not involved in the design, or conduct, or reporting, or dissemination plans of this research.

Patient consent for publication Not required.

Ethics approval The project was approved by the ethics committees of PGIMER Chandigarh; AllMS, New Delhi and GMCH, Chandigarh. NHM MP also approved the project. We implemented evidence-based strategies at the system level. No alterations were made in the management of individual patients.

Provenance and peer review Not commissioned; externally peer reviewed.

Data availability statement Data are available on request.

Open access This is an open access article distributed in accordance with the Creative Commons Attribution Non Commercial (CC BY-NC 4.0) license, which permits others to distribute, remix, adapt, build upon this work non-commercially, and license their derivative works on different terms, provided the original work is properly cited, appropriate credit is given, any changes made indicated, and the use is non-commercial. See: http://creativecommons.org/licenses/by-nc/4.0/.

ORCID iDs

Praveen Kumar http://orcid.org/0000-0003-4742-8787

Ashok Deorari http://orcid.org/0000-0002-4928-2497

\section{REFERENCES}

1 Askie LM, Darlow BA, Finer N, et al. Association between oxygen saturation targeting and death or disability in extremely preterm infants in the neonatal oxygenation prospective meta-analysis collaboration. JAMA 2018;319:2190-201.
2 Dauncey JW, Olupot-Olupot P, Maitland K. Healthcare-provider perceptions of barriers to oxygen therapy for paediatric patients in three government-funded eastern Ugandan hospitals; a qualitative study. BMC Health Serv Res 2019;19:335.

3 Thein OS, Chan CMT, McCance E, et al. Oxygen prescription: improving compliance using methods from BMJ Open Quality journal. BMJ Open Qual 2018;7:e000288.

4 Choudhury A, Young G, Reyad B, et al. Can we improve the prescribing and delivery of oxygen on a respiratory ward in accordance with new British thoracic Society oxygen guidelines? BMJ Open Qual 2018;7:e000371.

5 Ministry of Health and Family welfare, Government of India. Facility based newborn care operational guide, 2011. Available: http://164.100.130.11:8091/rch/FNBC_Operational_Guideline.pdf [Accessed 30 Jan 2021].

6 World Health Organization. Oxygen therapy for children, 2011. Available: https://apps.who.int/iris/bitstream/handle/10665/204584/ 9789241549554_eng.pdf [Accessed 14 Jan 2021].

7 Ogrinc G, Davies L, Goodman D, et al. SQUIRE 2.0 (standards for quality improvement reporting excellence): revised publication guidelines from a detailed consensus process. BMJ Qual Saf 2016;25:986-92.

8 Vento M, Escobar J, Cernada M, et al. The use and misuse of oxygen during the neonatal period. Clin Perinatol 2012;39:165-76.

9 Nangia S, Saili A, Dutta AK. Misuse of oxygen in a neonatal unit. Indian Pediatr 1998;35:262-4.

10 Sabherwal S, Gilbert C, Foster A, et al. Status of oxygen monitoring in four selected special care newborn units in India. Indian Pediatr 2020;57:317-20.

11 Kalyan G, Moxon S. The role of neonatal nurses in the prevention of retinopathy of prematurity. Indian Pediatr 2016;53 Suppl 2:S143-50.

12 Singh P, New M, Mon A, et al. A quality improvement project on improving the compliance of 'oxygen prescription with target saturations' in a district general hospital. Future Healthc $J$ 2020;7:s69-70.

13 Mittal S, Marlowe L, Blakeslee S, et al. Successful use of quality improvement methodology to reduce inpatient length of stay in bronchiolitis through judicious use of intermittent pulse oximetry. Hosp Pediatr 2019;9:73-8.

14 Kumar P, Chawla D, Thukral A, et al. Development of a quality improvement package for reducing sight-threatening retinopathy of prematurity. Indian J Ophthalmol 2020;68:115. 